\title{
Ultra-High-Performance Micellar Liquid Chromatography Comparing Tween 20 and Tween 40 for the Determination of Hydroxycinnamic Acids
}

\author{
Abd al-karim F. Ali ${ }^{1}$ (D) and Neil D. Danielson ${ }^{2, *}$ \\ 1 Department of Chemistry College of Education for Pure Sciences, University of Diyala, \\ Baqubah MJJ2+R9G, Iraq; abdalkarim.ali@uodiyala.edu.iq \\ 2 Department of Chemistry and Biochemistry, 651 E. High Street, Miami University, Oxford, OH 45056, USA \\ * Correspondence: danielnd@miamioh.edu
}

Citation: Ali, A.a.-k.F.; Danielson, N.D. Ultra-High-Performance Micellar Liquid Chromatography Comparing Tween 20 and Tween 40 for the Determination of

Hydroxycinnamic Acids. Separations 2022, 9, 61. https://doi.org/10.3390/ separations 9030061

Academic Editor: Marcello Locatelli

Received: 29 December 2021

Accepted: 21 February 2022

Published: 26 February 2022

Publisher's Note: MDPI stays neutral with regard to jurisdictional claims in published maps and institutional affiliations.

Copyright: (C) 2022 by the authors. Licensee MDPI, Basel, Switzerland. This article is an open access article distributed under the terms and conditions of the Creative Commons Attribution (CC BY) license (https:// creativecommons.org/licenses/by/ $4.0 /)$.

\begin{abstract}
A simple and green ultra-high-performance micellar liquid chromatography (MLC) method was developed here, comparing Tween 20 and Tween 40 for the first time as the only mobile phase modifiers with a C18 column. Its application to the separation of nine hydroxycinnamic acid (HCA) derivatives (cinnamic, caffeic, ferulic, sinapic, o-, m-, p-coumaric, 3,4-dihydroxyhydrocinnamic, and chlorogenic acids) was made, due to their importance as antioxidants in a variety of natural beverages such as wine and coffee. The optimal conditions of $45^{\circ} \mathrm{C}$ temperature (T), $1 \%$ surfactant in the mobile phase, and $\mathrm{pH}$ control with $2.5 \mathrm{mM}$ sulfuric acid were determined and used to elucidate the analytical figures of merit. Although the effect of these conditions was insignificant between the two surfactants, the nine-component HCA mixture was separated faster-in about $15 \mathrm{~min}$-and with less peak tailing using Tween 20 than with Tween 40. The linearity of the Van't Hoff (lnk versus 1/T) plots was evident for Tween 20, indicating a single retention mechanism-but less so for Tween 40 . The equilibrium constants of the analytes with the micelles and the stationary phase were calculated. The developed method was successfully used to analyze organic red wine, spiked organic red wine, and green coffee diet pills. The percent recoveries of the nine HCA compounds spiked in the organic red wine ranged from $90 \%$ to $107 \%$. The green coffee extract diet pills showed the presence of a significant amount of chlorogenic acid.
\end{abstract}

Keywords: micellar liquid chromatography; Tween surfactants; hydroxycinnamic acid derivatives

\section{Introduction}

Micellar liquid chromatography (MLC) is a modified reverse-phase liquid chromatography approach in which a surfactant is used as a mobile phase (MP) modifier above its critical micellar concentration (CMC). The various equilibria, involving the partitioning of the solute with the aqueous phase, the micellar phase and the surfactant-coated stationary phase, are well known [1]. The role of surfactants in analytical chemistry, particularly chromatography, has been reviewed recently [2]. Mainly, only three surfactants are used in the chromatography literature: the anionic sodium dodecyl sulfate (SDS), the cationic cetyltrimethylammonium bromide (CTAB), and the neutral polyoxyethylene (23) lauryl ether (Brij-35). A comparison of these three previously mentioned surfactants for the MLC of plant extracts such as fatty acids and polyphenols in the thin layer mode has been reported [3]. Recent uses of CTAB seem to be more directed towards micellar electrokinetic chromatography, such as to facilitate the separation of fluoroquinolines with a negatively applied voltage [4]. Although Brij-35 was first used to test the viability of nonionic MLC [5], it has been more recently used in a SDS mixed micellar mobile phase to separate amino acids [6], and pharmaceutical mixtures such as common cold medicines [7] and sulfonamides [8]. Variations in Brij-35 in both the alkyl ether chain and the polyoxyethylene chain have been tested for the separation of a few compounds in each class (sulfonamides, 
$\beta$-adrenoceptor antagonists, tricyclic antidepressants, and flavonoids) [9]. However, this dominance of the use of SDS for MLC was evident in a recent review focusing on pharmaceuticals [10]. Our previous work on ultra-high-performance MLC has also tended to focus on the use of SDS. In particular, mono- and di-substituted hydroxyl aromatic acids, plus the phthalic acid isomers, were separated in various different mixes-again, isocratically with a C18 column and $0.1 \%$ SDS in dilute sulfuric acid, usually in less than $10 \mathrm{~min}$. [11]. Various mono-, di-, and tri-carboxylated aromatics, and eight impurities that were formed in the synthesis of terephthalic acid, were separated isocratically on a C18 column in about 17 min using 1\% SDS adjusted to $\mathrm{pH} 3$ [12]. A recent study involving the separation of the same terephthalic acid impurities, but using simply a C18 column coated with the nonionic surfactant polyoxyethylene (20), sorbitan monolaurate (Tween 20) and present at $0.001 \%$ or less in the isocratic mobile phase, was possible in under $20 \mathrm{~min}$ [13].

Our continued interest is in the better understanding of the capabilities of Tween surfactants, an understudied type of nonionic surfactant, in MLC. A recent MLC review article did not mention any specific Tween applications [14]. Initially, Tween 20 was used to facilitate chiral separations of various pharmaceuticals, such as naproxen, by reducing separation times without loss of resolution [15-17]. MLC with Tween 20 was found to simplify sample pre-treatment when coupled to an immunoassay for cortisol [18]. Tween 80 was found to increase analyte retention on a phenyl column using a cholic acid artificial membrane component in the mobile phase [19]. The alkaloids tetrandrine and fangchinoline were separated on a microfluidic micellar electrokinetic capillary chromatography system using 3\% Tween 20 with 5\% methanol in an acetate run buffer at $\mathrm{pH} 5.5$ [20]. The reverse-phase separation of some phenolic acid or catecholamine mixtures using mixed ionic surfactant (tetradecyltrimethylammonium or SDS)-Tween mobile phases has been introduced [21], but apparently not followed up on. Recently, there has been a study involving the enhanced partitioning of phenolic acids-when dissolved in a $1 \%$ Tween 20 solution -into methyl linoleate, a hydrophobic lipid phase. In particular, hydroxyl cinnamic acids such as sinapic, ferulic, and caffeic acids were increased a proportion of $35-50 \%$ in the lipid phase as compared to the Tween aqueous phase- substantially higher than the 1-10\% increase in the lipid phase when compared to just water [22]. Therefore, it was surmised that Tween surfactants might accentuate retention with a C18 stationary phase (representing the lipid), and therefore, an MLC study using Tween surfactants of hydroxycinnamic acid (HCA) compounds was proposed. The importance of the separation and determination of HCA compounds is summarized as follows.

HCA derivatives are a very important class of natural compounds and play a significant role in the metabolic pathways for building lignin in plants. Lignin gives plant cell walls necessary mechanical support, making it the second most abundant natural polymer after cellulose $[23,24]$. Ferulic acid (4-hydroxy-3-methoxycinnamic acid) is covalently bonded to lignin, and is also found in grains, cereals, spices, and fruits [25-27]. In plants, HCA derivatives accumulate as a response to environmental or pathological stresses such as microbial infections, UV radiation, or wounding, due to their anti-inflammatory, antioxidant, and antimicrobial properties. Figure 1 shows the metabolic pathways of HCA derivative biosynthesis in plants; phenylalanine is the starting material for cinnamic acid [28-30].

The presence of HCA derivatives in some fruits, such as apples and grapes, in significant amounts is the reason for the powerful antioxidant properties of these fruits. Juices and wines made of these fruits also contain HCA derivatives, which play an additional role in the quality, color, taste, and character of the final product [33-36]. During the fermentation and aging of wine, the concentration of HCA derivatives can be used for the estimation of the quality of the aged wine [37,38], because these compounds are naturally converted into volatile hydroxybenzoic acid derivatives, which have a significant effect on the aroma and taste of the aged wine $[39,40]$. 


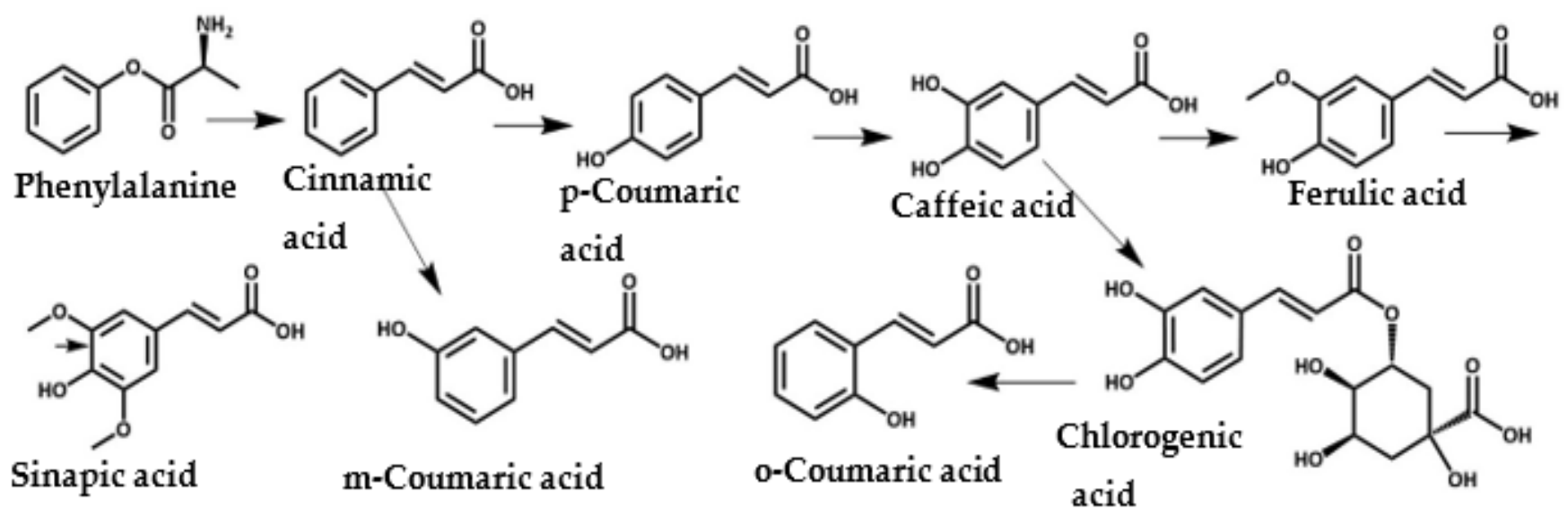

Figure 1. Natural biosynthesis map of cinnamic acid derivatives in plants [31,32].

The determination of HCA derivatives is of crucial importance due to its availability in food, beverages, and medications. Due to the nature of most samples, the most widely used method for the determination of HCA derivatives is RPLC with UV detection [41]. Previous determinations of four HCA derivatives in orange juice have used RPLC with a complex mobile phase composition, including the non-environmentally friendly tetrahydrofuran solvent [42]. Phenolic acids, including some HCAs, have been determined in cereals after solid phase extraction using a methanol linear solvent gradient [43]. Phenolic acids, including chlorogenic and caffeic acids as well as flavonoids - 17 in number-have been previously separated in about $70 \mathrm{~min}$ by RPLC using a similar methanol gradient [44]. A previous ultra-high-performance liquid chromatography (UHPLC) method with UV detection for the qualitative and quantitative analysis of CA derivatives and flavonoids required a six-step gradient elution using acetonitrile, with a simultaneous flowrate gradient, to give a separation in about $11 \mathrm{~min}$ [45]. A comparative study of HPLC and UHPLC for phenolic compounds using sub-2 micron particle columns has been applied to grape wines and teas [46]. MLC has also been applied for the separation of phenolic compounds; a few phenolic compounds (tyrosol, caffeic acid, p-coumaric acid, and oleuropeona), along with two phospholipids, have been separated on a C18 column with $0.07 \mathrm{M}$ SDS and 2.5\% 2-propanol [47]. Phenolic acids, separately or combined with flavonoids, have been separated using three different RPLC modes, with SDS and propanol modified mobile phases at both above and below the CMC [48,49].

To our knowledge, there are no reports of the MLC of HCA compounds-particularly in the UHPLC mode, and certainly not one involving a comparison of Tween surfactants. A comparison study that uses both Tween 20 and Tween 40 (Figure 2) as the only isocratic MP modifiers above their CMC is presented in this paper. Although gradient elution studies using an organic solvent with MLC have been reported [50,51], an important aspect of our study was to avoid the use of any organic modifier solvents in the mobile phase and to maintain the inherent "green" advantage of MLC [52].

The optimization of temperature, sulfuric acid concentration, and the percentage of surfactant was investigated for both surfactants separately for the separation of a mixture of nine HCA derivatives, listed in Table 1. The retention mechanism with respect to Van't Hoff plots was explored and MLC equilibrium constants with respect to micellar stationary phase interactions were calculated. Quantitative analysis followed the determination of the optimal chromatographic conditions. Analytical figures of merits were calculated for both surfactants based on triplicate measurements, but the determination of HCA derivatives in organic red wine, organic red wine spiked with a mixture containing $20 \mathrm{mg} / \mathrm{L}$ of the nine CA derivatives under investigation, and a green coffee extract diet pill was performed using Tween 20. 


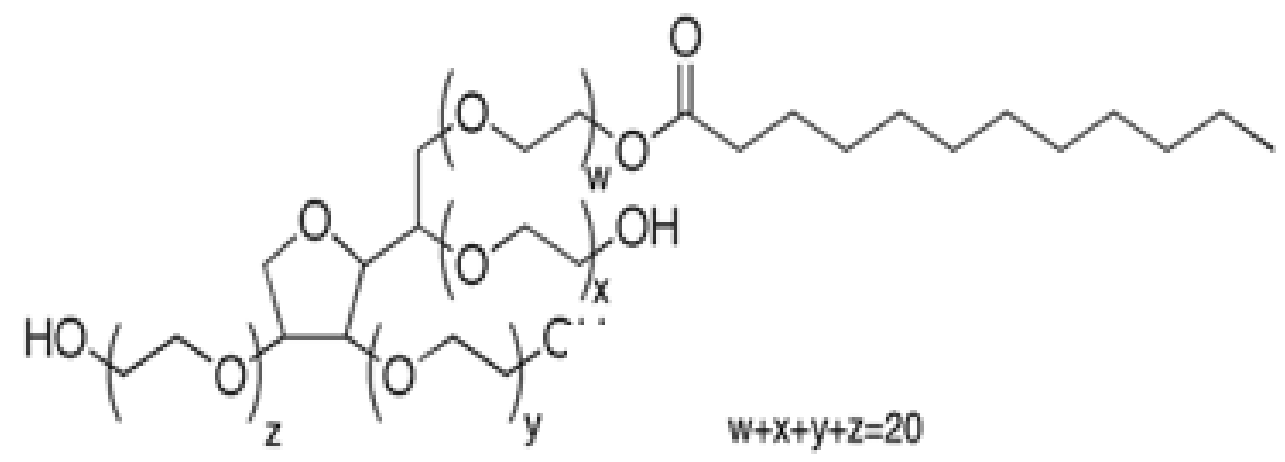

Figure 2. The structure of Tween $20(\mathrm{~W}+\mathrm{X}+\mathrm{Y}+\mathrm{Z}=20)$ with primarily $(60 \%) \mathrm{C} 12$ alkyl chains; molar mass 1228. Tween 40, also with ( $\mathrm{W}+\mathrm{X}+\mathrm{Y}+\mathrm{Z}=20)$, has primarily (90\%) C16 alkyl chains; molar mass 1277.

Table 1. List of cinnamic acid derivatives with their corresponding acid dissociation constant pKa.

\begin{tabular}{lccc}
\hline & Name & Abbreviation & pKa \\
\hline 1 & Chlorogenic & Clg & 3.50 \\
2 & 3,4-Dihydroxy-hydrocinnamic & Dhc & 4.62 \\
3 & Sinapic & Sip & 4.47 \\
4 & Ferulic & Fer & 4.52 \\
5 & Caffeic & Caf & 4.43 \\
6 & p-Coumaric & pCm & 4.10 \\
7 & m-Coumaric & mCm & 4.44 \\
8 & o-Coumaric & oCm & 4.04 \\
9 & Cinnamic & Cin & 4.44 \\
\hline
\end{tabular}

\section{Materials and Methods}

\subsection{Chemicals and Samples}

Distilled deionized water was purified through a Milli-Q (Millipore, Bedford, MA, USA) water purification system and treated on-line with UV light before using it to prepare all the necessary solutions. The mobile phase was acidified with appropriate concentrations of sulfuric acid that was diluted from $98 \%$ sulfuric acid, purchased from Fisher Scientific (Pittsburgh, PA, USA). Trans-cinnamic acid ( $>98 \%$ pure), ferulic acid (99\% pure), 3,4dihydroxyhydrocinnamic acid (98\%), sinapic acid (98\%), o-coumaric $(97 \%), \mathrm{m}$-coumaric (99\%), p-coumaric (98\%), caffeic acid (98\%), chlorogenic acid (95\%), Tween 20, and Tween 40 (molecular biology grade) were purchased from Sigma-Aldrich (St. Louis, MO, USA). Names, abbreviations, and the dissociation constants of HCA derivatives analyzed in this work are listed in Table 1.

Analytical figures of merit were calculated for both surfactants based on triplicate measurements to generate a six-point calibration curve for each surfactant. The Tween 20generated calibration curve was successfully used for the determination of HCA derivatives in organic red wine, organic red wine spiked with a mixture containing $20 \mathrm{mg} / \mathrm{L}$ of the nine CA derivatives under investigation, and a green coffee extract diet pill. The standard mixture of the nine HCA derivatives were prepared by mixing $10 \mathrm{mg}$ of each in $100 \mathrm{~mL}$ of $60 \%$ methanol- $-40 \% \mathrm{H}_{2} \mathrm{O}$, and then sonicating for $10 \mathrm{~min}$. Two samples were analyzed for their HCA derivative content. Organic red wine (Flourish wine of California) was filtered through a $0.22 \mu \mathrm{m}$ nylon filter before direct column injection without further treatment. Two green coffee diet pills (Garcinia Cambogia by Purely Inspired) were dissolved in $100 \mathrm{~mL}$ of $60 \%$ methanol- $40 \% \mathrm{H}_{2} \mathrm{O}$ and then filtered using a $0.22 \mu \mathrm{m}$ plastic filter before injection for analysis. 


\subsection{Instrumentation and Chromatographic Conditions}

Chromeleon 7.2.9 software (Thermo Scientific, Sunnyvale, CA, USA) was used to control the UltiMate 3000 UHPLC instrument (Thermo Scientific, Sunnyvale, CA, USA) and also to generate the necessary data. The UHPLC system was equipped with a DGP 3600RS pump, online degasser, and a WPS 3000RS autosampler. The column temperature was controlled using a TCC-3000RS oven and UV detection by the Ultimate multiwavelength 3000RS detector.

All chromatography was carried out using a Phenomenex Luna Omega polar C18 UHPLC column (Torrance, CA, USA). The dimensions of this column were $150 \mathrm{~mm} \times 2.1 \mathrm{~mm}$, with a $1.6 \mu \mathrm{m}$ particle diameter. This column has polar modified surface-particles with a pore size of $100 \AA$, a surface area of $260 \mathrm{~m}^{2} \cdot \mathrm{g}^{-1}$, and carbon load of $11 \%$. Before starting the MLC experiments, one of the mobile phases (1\% vol/vol Tween 20 or 1\% vol/vol Tween 40), acidified using $5 \mathrm{mM}$ sulfuric acid solution, was used to equilibrate the column for at least $15 \mathrm{~min}$ at a flow rate of $0.1 \mathrm{~mL} / \mathrm{min}$ to ensure the full adsorption of the surfactant on the column stationary phase. The optimization and the quantitative analysis were performed using isocratic conditions at $0.3 \mathrm{~mL} / \mathrm{min}$, with single wavelength detection at $270 \mathrm{~nm}$.

\section{Results and Discussion}

The main goal of this study was to compare the effectiveness of Tween 20 and Tween 40 as mobile phase modifiers for ultra-high-performance MLC of HCA derivatives. The first step was the optimization of temperature for both surfactants. Optimization of sulfuric acid concentration and the percentages of Tween 20 and Tween 40 was performed at $45^{\circ} \mathrm{C}$. The Tween mobile phase concentrations ranged between 0.6 and $1.2 \%$ (about $4.5-10 \mathrm{mM}$ for both Tween 20 and Tween 40). The CMC values of Tween 20 and Tween 40 were, respectively, $0.050 \mathrm{mM}$ and $0.028 \mathrm{mM}$ at $25^{\circ} \mathrm{C}$, and only decreased to, respectively, $0.034 \mathrm{mM}$ and $0.028 \mathrm{mM}$ at $40^{\circ} \mathrm{C}[53,54]$. As there was no organic modifier, the micellar mobile phases (at least 100 times over the CMC values) were definitely maintained throughout this study. The second goal was to employ the optimum chromatographic conditions for the qualitative and quantitative analysis of three samples using a calibration curve.

\subsection{Retention as a Function of Temperature}

The optimization of temperature was performed using mobile phases of $2.5 \mathrm{mM}$ sulfuric acid with 1\% Tween 20 (Figure 3A), and the same acid concentration with 1\% Tween 40 (Figure 3B). A direct comparison between the two surfactants shows that Tween 20 had a consistently slightly lower retention factor range (about 3 units) than Tween 40 over the same range of temperatures. The shorter alkyl chain of the bound Tween 20 probably prevents easy analyte retention past the more hydrophilic polyoxyethylene unit to the stationary phase. Tween 40, with the longer alkyl chain, provides better access and sets up a more hydrophobic stationary phase. However, this also indicates that increasing the temperature is more effective in the reduction of the retention factor in the case of using Tween 40 as the mobile phase modifier. Increasing the temperature may loosen the micelle clusters, which could be more pronounced for Tween 40, causing a stronger analyte presence with this mobile phase and reduced retention (better analysis time). A close inspection of both the Tween 20 and 40 plots at high $\mathrm{k}$ values shows there appears to be a slight drop in the retention factor at about $36{ }^{\circ} \mathrm{C}$. Such transitions have been reported previously for completely reverse-phase HPLC, and are due to a change in the orientation of the bonded phase [55]. As the mobile phase viscosity decreases as the temperature increases, MLC efficiency is often improved due to the improved transfer of the analyte between the aqueous and micellar phases and the stationary phase [56]. The subsequent increase in the analyte diffusion constant causes a decrease in mass transfer in the mobile phase term $(\mathrm{Cm})$ in the van Deemter equation-improving the column efficiency. A temperature of $45^{\circ} \mathrm{C}$ was considered to be optimal. 


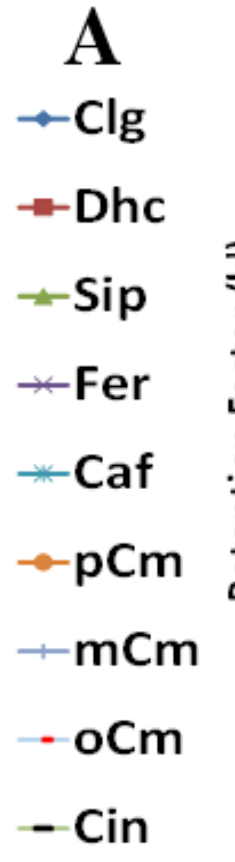

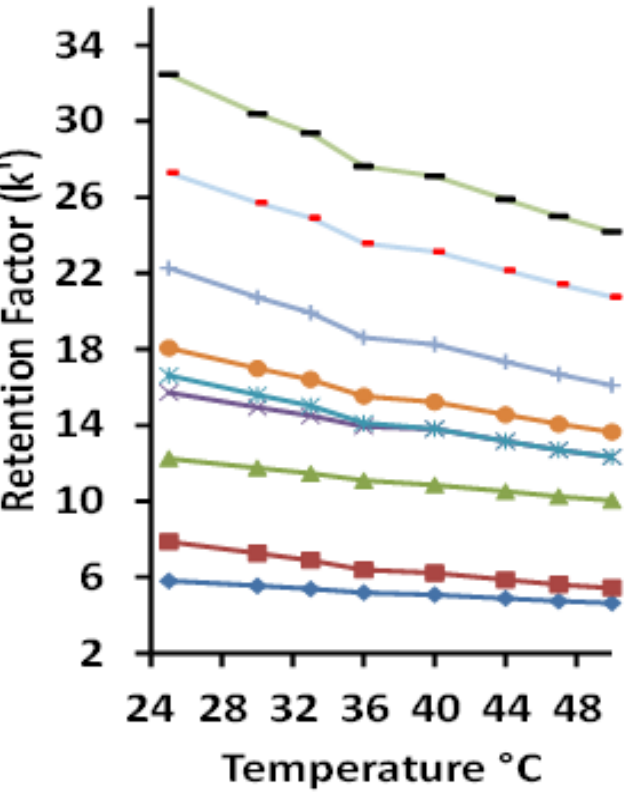

B

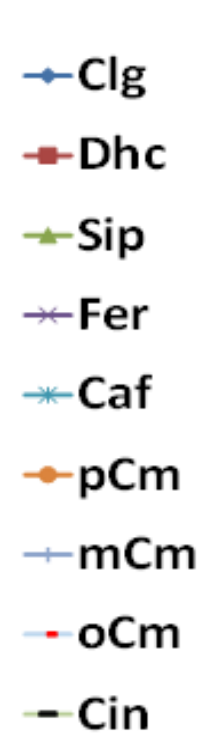

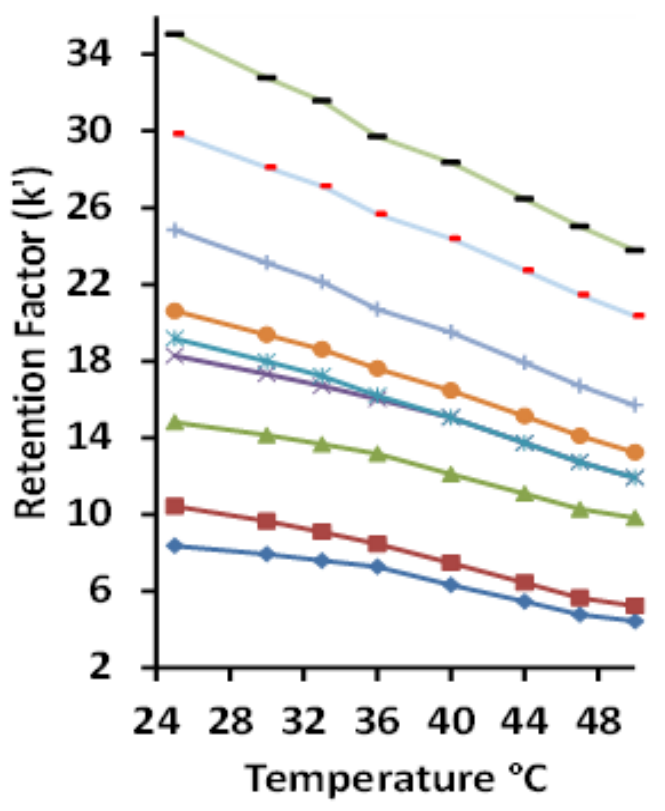

Figure 3. The relationship between the retention factor $(\mathrm{k})$ and the temperature using Tween 20 (A) and Tween 40 (B).

The linear relationship of the $\ln$ retention factor $(\mathrm{k})$ versus $1 /$ Temperature $(\mathrm{T})$, where the intercept " $\mathrm{A}$ " is a measure of the entropy and slope " $\mathrm{B}$ " is a measure of the enthalpy, is considered valid for an analyte that is undergoing retention through one mechanism [57]. Based on the nine analyte trends in Figure S1 of the Supplementary Information for Tween 20, and the six for Tween 40 in Figure S2, data for the intercept and slope are tabulated in Tables 2 and 3 for the HCAs. Correlation coefficients of 0.99 or better were found for all nine analytes using Tween 20, but a little lower for the six Tween 40 analytes. For Tween 20, the slope values for the six longest-retained analytes were fairly similar, in the 1100 range. For the three least-retained compounds, Clg and Sip was smaller and Dhc larger. The intercept values were more varied, from about minus 0.1 to -1.1 , with Sip being the smallest and Dhc the largest—with both outside that range. Both the enthalpy and entropy values were less than those previously found for the separation of di- and tri-carboxylic acids using Tween 20, which were in the 1800 and -4 ranges, respectively [13]. For Tween 40, six of the analytes showed linear plots with more of a decreasing trend, from about 1800 to 1500 for the slope, and higher intercept values in the minus 2-3 range. These increased slope or intercept values indicate a greater respective enthalpy or entropy change, involving the transfer of the solute from the aqueous phase to the stationary phase. However, because the slopes tend to decrease with increasing retention, the linear fit model may not be quite appropriate. The plots for the three least-retained analytes (Clg, Dhc, and Sip) using Tween 40 were less linear $\left(\mathrm{R}^{2}\right.$ values $\left.0.94-0.96\right)$, and a quadratic fit of the data in the form of the equation $\ln k^{\prime}=a+b(1 / T)+c(1 / T)^{2}$ was performed, as shown in Figure 4 . The plots appear to have two linear portions, with a transition temperature of $310^{\circ} \mathrm{K}$. This is similar to the transition temperature of $303^{\circ} \mathrm{K}$ observed for PAHs [58], and is somewhat higher than that of $298^{\circ} \mathrm{K}$ observed previously for Tween 20 with di-and tri-carboxylic acid compounds [13]. As the $\mathrm{pH}$ of the mobile phase was about 2.3, all of the analytes except $\mathrm{Clg}$ (pKa 3.5) would be in their completely unionized form, and therefore, a combination of an ionized and neutral analyte causing mixed retention cannot explain the nonlinearity of ln $\mathrm{k}^{\prime}$ with $1 / \mathrm{T}$. These three analytes (Clg, Dhc, and Sip) were the least retained, and perhaps their interaction with the Tween 40 micelle became the more significant retention mechanism, in contrast to the greater degree of stationary phase retention of the other six analytes. The Ln k linearity is also indicative that the integrity of the micelle was retained 
over the studied temperature range. This could be less likely for the Tween 40 micelle, which is less compactly packed compared to Tween 20, due to the longer alkyl chain. By taking the derivative of the quadratic equation and setting it to zero, the temperature at the extreme (maximum in this case) value of $\mathrm{k}$ can be determined as $\mathrm{T}=-2 \mathrm{c} / \mathrm{b}$. These corresponding T values, when multiplied by 1000 for Clg, Dhc, and Sip, were 296, 291, and $291^{\circ} \mathrm{K}$, respectively_indicating the maximum temperature for an entropy-driven process. Our lowest experimental temperature was slightly above these temperatures, indicating that the retention process was mostly enthalpy-driven [57].

Table 2. Coefficients $A$ and $B$ with correlation coefficients $\left(R^{2}\right)$ for plots based on the van't Hoff equation: $\ln k=A+B(1 / T)$, shown in Figure S1 for Tween 20 .

\begin{tabular}{cccc}
\hline Compound & A Intercept & B Slope & $\mathbf{R}^{\mathbf{2}}$ \\
\hline Clg & -1.15 & 867 & 0.9973 \\
Dhc & -2.73 & 1425 & 0.9902 \\
Sip & -0.0676 & 767 & 0.9978 \\
Fer & -1.05 & 1150 & 0.9927 \\
Caf & -1.05 & 1150 & 0.9927 \\
pCm & -0.695 & 1068 & 0.9935 \\
mCm & -1.04 & 1234 & 0.9912 \\
oCm & -0.183 & 1039 & 0.9931 \\
Cin & -0.280 & 1119 & 0.9919 \\
\hline
\end{tabular}

Table 3. Coefficients $A$ and B with correlation coefficients $\left(R^{2}\right)$ for plots based on the van't Hoff equation: $\ln k=A+B(1 / T)$, shown in Figure S2 for Tween 40 .

\begin{tabular}{cccc}
\hline Compound & A Intercept & B Slope & $\mathbf{R}^{\mathbf{2}}$ \\
\hline Fer & -3.29 & 1873 & 0.9828 \\
Caf & -3.29 & 1873 & 0.9828 \\
pCm & -2.76 & 1735 & 0.9831 \\
mCm & -2.75 & 1786 & 0.9895 \\
oCm & -1.58 & 1489 & 0.9897 \\
Cin & -1.47 & 1501 & 0.9935 \\
\hline
\end{tabular}

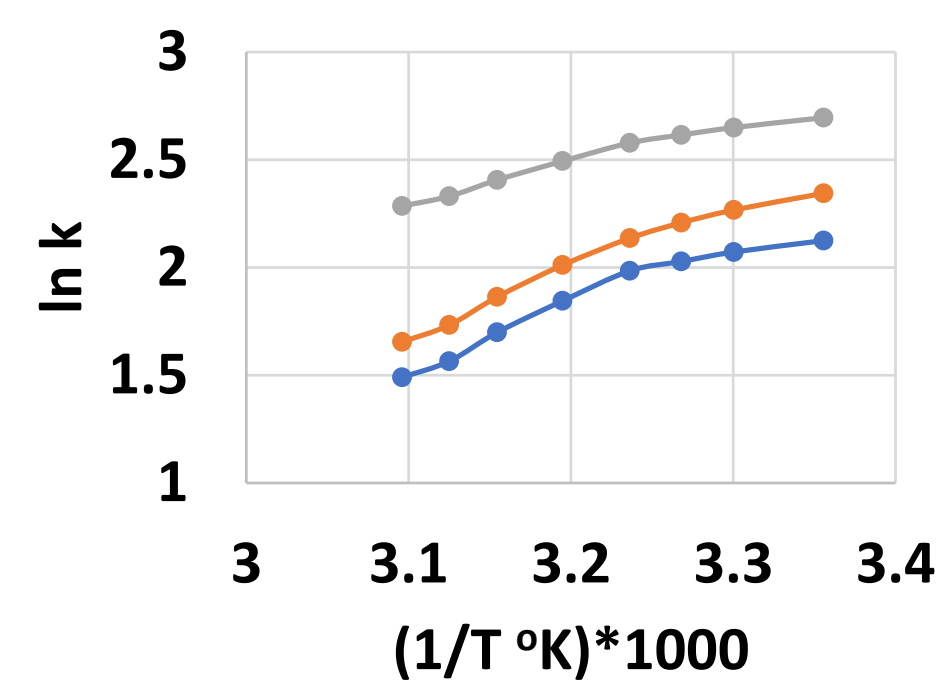

Figure 4. Plots of $\ln$ retention factor $\mathrm{k}$ versus $\left(1 / \mathrm{T}^{\circ} \mathrm{K}\right)^{*} 1000$ using data in Figure $\mathrm{x}$ for $\mathrm{Clg}$, Dhc, and Sip. Quadratic equation data fit: $\mathrm{Clg}, \mathrm{y}=-8.16 \mathrm{x}^{2}+55.21 \mathrm{x}-91.23, \mathrm{R}^{2}=0.9944 ;$ Dhc, $\mathrm{y}=-6.40 \mathrm{x}^{2}+$ $44.03 x-73.35, R^{2}=0.9974 ;$ Sip, $y=-3.88 x^{2}+26.65 x-43.08, R^{2}=0.9963$. 


\subsection{Retention as a Function of Sulfuric Acid Concentration}

Both surfactants have very similar responses to the effects of changing sulfuric acid concentrations on the retention factors of the nine HCA derivatives (Figure 5A for Tween 20 and Figure 5B for Tween 40). As expected, retention due to the ionization of the $\mathrm{COOH}$ group was lowest with no acid, and increased to a plateau starting at $2 \mathrm{mM}$ sulfuric acid, when little ionization was left. The retention order of the nine acids is listed in order in Table 1 and is not really related to pKa. Although it had the lowest pKa, chlorogenic acid was retained the least, likely due to its hydrophilic ester group. For both surfactants, resolution was lost for SA and FA at around $1 \mathrm{mM}$ sulfuric acid to $0 \mathrm{mM}$ acid, which might be due to the similar structures and pKa values for these two acids. The optimum sulfuric acid concentration was considered to be $2.5 \mathrm{mM}$.
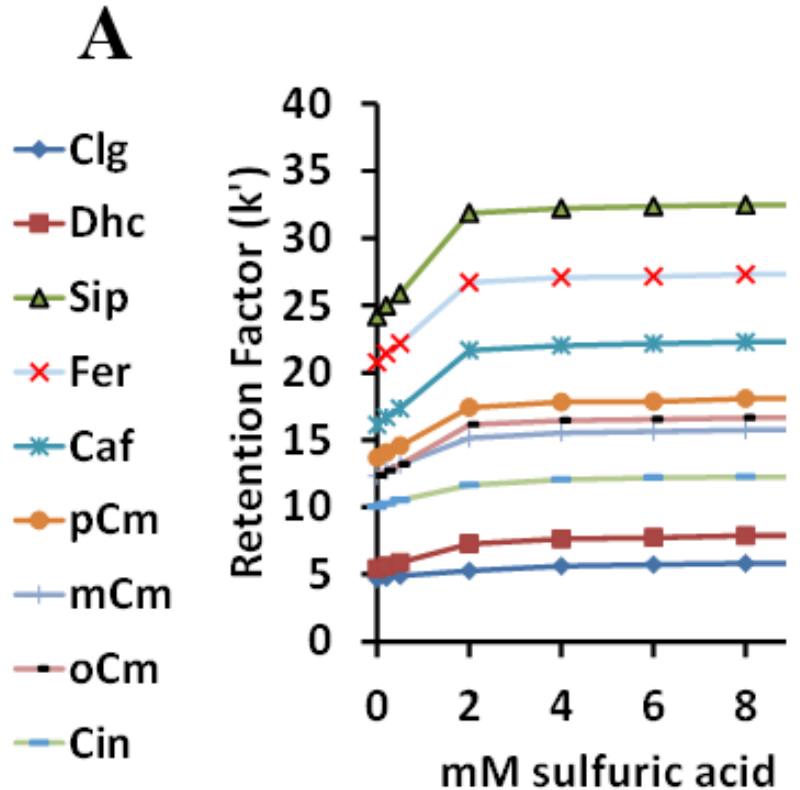

B

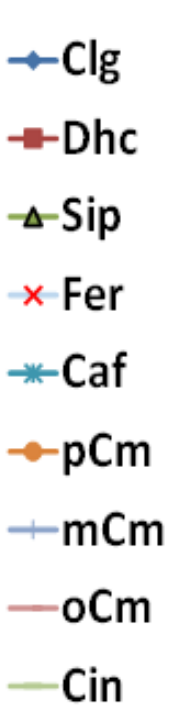

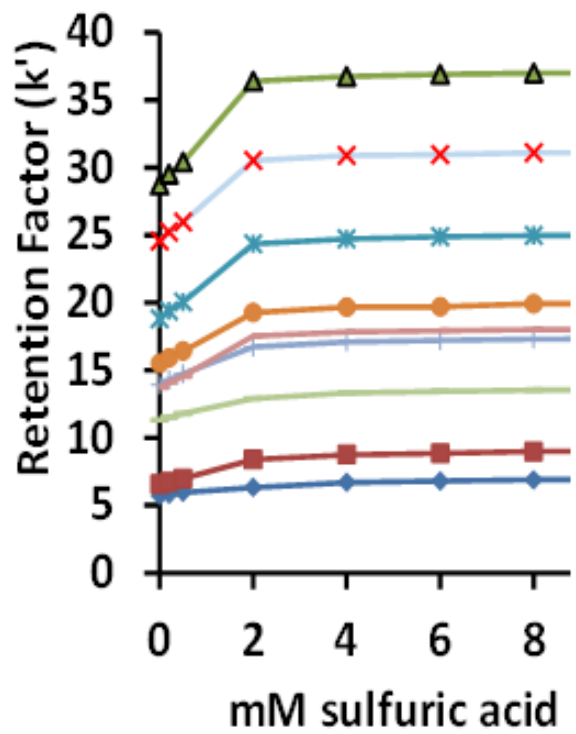

Figure 5. The relationship between the retention factor $(\mathrm{k})$ and the sulfuric acid concentration using Tween 20 (A) and Tween 40 (B).

\subsection{Retention as a Function of Tween 20 and Tween 40 Percentage}

With a temperature of $45{ }^{\circ} \mathrm{C}$ and a sulfuric acid concentration of $2.5 \mathrm{mM}$, the percentages of Tween 20 and 40 were varied from $0.6-1.2 \%$ (Figure 6). Due to the closely related structures of these Tween surfactants, the retention factors profiles were, as expected, quite similar. No retention factor crossovers were noted, with the retention factors consistently higher for Tween 40 than Tween 20. The retention order of the HCA derivatives was generally as expected based on their nonpolar structures, with the most hydrophilic compounds ( $\mathrm{CgA}$ and Dhc) with multiple hydroxyl groups retained the least, the p-,m-.o- coumarics in their expected order, and cinnamic acid (no hydroxyl group) retained the most. The sinapic, ferulic, and caffeic acid retention order was less easy to predict, but was the same as their partitioning affinity from Tween to the methyl linoleate lipid phase, as described previously in the Introduction of [22]. Considering peak resolution and analysis time, the optimum Tween percentage was considered to be $1 \%$.

For completely aqueous MLC, the partitioning of the analytes between the micelles and the surfactant-coated stationary phase are the important equilibria [59]. The partitioning equilibrium constants $\mathrm{K}$ can be determined from the following Equation (1):

$$
1 / \mathrm{k}=1 /\left(\varphi \mathrm{K}_{\mathrm{AS}}[\mathrm{S}]\right)+\mathrm{K}_{\mathrm{AM}}[\mathrm{M}] /\left(\varphi \mathrm{K}_{\mathrm{AS}}[\mathrm{S}]\right)
$$

where $\mathrm{k}$ = retention factor, $\mathrm{K}_{\mathrm{AS}}$ is the analyte equilibrium constant between the stationary and aqueous phases, $\mathrm{K}_{\mathrm{AM}}$ is the analyte-micelle equilibrium constant per monomer of 
surfactant, and $\mathrm{M}$ is the concentration of the surfactant in the mobile phase [60]. The ratio of the slope to the intercept of Equation (1) gives the $\mathrm{K}_{\mathrm{AM}}$ value. The equilibrium constant per micelle $\mathrm{K}_{\mathrm{eq}}$ is $\mathrm{K}_{\mathrm{AM}}\left(\mathrm{N}_{\mathrm{agg}}\right)$, where $\mathrm{N}_{\text {agg }}$ is the aggregation number for the surfactant-about 90 for both Tween 20 and Tween 40 [60,61]. Such linear plots, using Equation (1) for all the analytes, are shown for Tween 20 in Figure S3 and for Tween 40 in Figure S4. The slope and intercept data shown in Table 4 for Tween 20 are again based a higher correlation coefficient (usually 0.99) than the analogous data in Table 5 for Tween 40 (usually 0.98). The $\mathrm{K}_{\mathrm{AM}}$ values, ranging from about 100-300 for the analytes separated using Tween 40 (Table 5), did not show a strong correlation with retention order and were significantly higher than those for Tween 20 (range of 25-130 in Table 4), which did show more of a trend with retention order. The compound with the strongest retention for the micelle as measured by $\mathrm{K}_{\mathrm{AM}}$ also differed: Dhc using Tween 40 and oCm for Tween 20 . The analyte attraction for the stationary phase as measured by $\varphi \mathrm{K}_{\mathrm{AS}}[\mathrm{S}]$, where $\varphi$ is the phase ratio and [S] is the stationary phase sites, did tend to follow the retention order trend for Tween 20 (Table 4) and Tween 40 (Table 5). The highest $\varphi \mathrm{K}_{\mathrm{AS}}[\mathrm{S}]$ values were the two most-retained compounds (oCm and $\mathrm{Cin}$ ) for both surfactants.

A

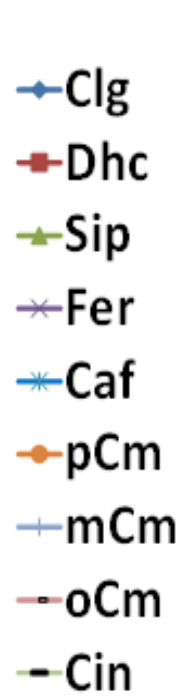

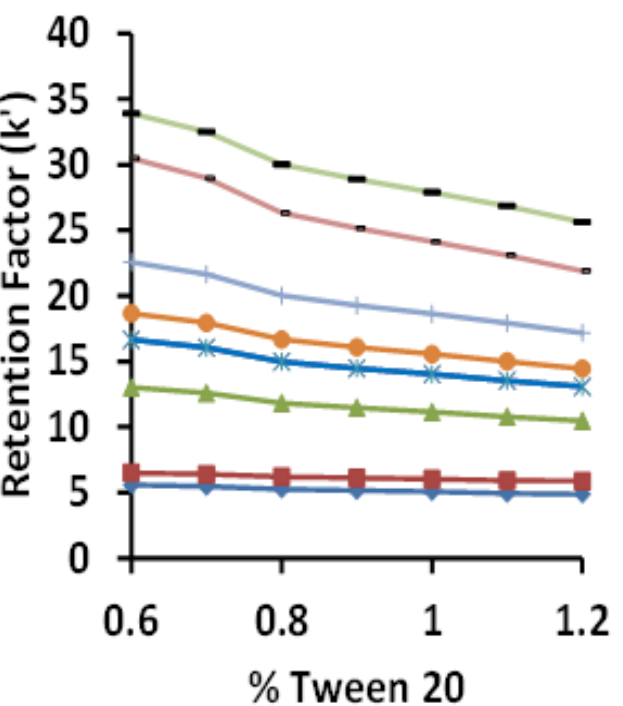

B
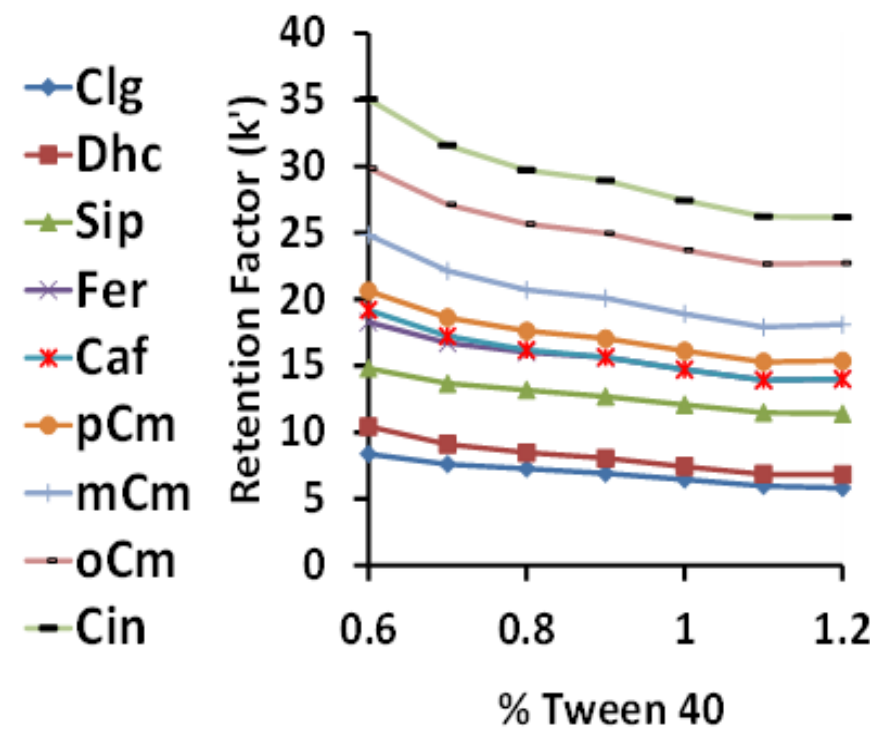

Figure 6. The relationship between the retention factor $(k)$ and the surfactant concentration using Tween 20 (A) and Tween 40 (B).

Table 4. Linear regression equations for $1 / \mathrm{k}$ vs. [Tween 20, $\mathrm{mM}$ ] plots (Figure S3 data) for HCAs. and their equilibrium constants (Equation (1) in above text).

\begin{tabular}{cccccc}
\hline Compound & Intercept & Slope $^{*} \mathbf{1 0 0 0}$ & $\mathbf{R}^{\mathbf{2}}$ & $\mathbf{K}_{\mathbf{A M}}$ & $\mathbf{\Phi K}_{\mathbf{A S}}[\mathbf{S}]$ \\
\hline Clg & 0.154 & 5.37 & 0.9861 & 34.9 & 6.50 \\
Dhc & 0.138 & 3.44 & 0.9790 & 25.0 & 7.26 \\
Sip & 0.0585 & 3.85 & 0.9897 & 65.8 & 17.1 \\
Fer & 0.0440 & 3.37 & 0.9902 & 76.6 & 22.7 \\
Caf & 0.0440 & 3.37 & 0.9902 & 76.6 & 22.7 \\
pCm & 0.0383 & 3.20 & 0.9908 & 83.6 & 26.1 \\
mCm & 0.0308 & 2.83 & 0.9907 & 91.9 & 32.5 \\
oCm & 0.0203 & 2.61 & 0.9907 & 128.6 & 49.3 \\
Cin & 0.0203 & 1.93 & 0.9907 & 95.1 & 49.3 \\
\hline
\end{tabular}


Table 5. Linear regression equations for $1 / \mathrm{k}$ vs. [Tween $40, \mathrm{mM}$ ] plots (Figure S4 data without $9.4 \mathrm{mM}$ point) for HCAs and equilibrium constants (Equation (1) in above text).

\begin{tabular}{cccccc}
\hline Compound & Intercept & Slope $^{*} \mathbf{1 0 0 0}$ & $\mathbf{R}^{\mathbf{2}}$ & $\mathbf{K}_{\mathbf{A M}}$ & $\mathbf{\Phi K}_{\mathbf{A S}}[\mathbf{S}]$ \\
\hline Clg & 0.0656 & 11.6 & 0.9869 & 176 & 15.2 \\
Dhc & 0.0411 & 12.1 & 0.9881 & 294 & 24.3 \\
Sip & 0.0462 & 4.74 & 0.9897 & 103 & 21.7 \\
Fer & 0.0310 & 4.75 & 0.9849 & 153 & 32.3 \\
Caf & 0.0364 & 4.06 & 0.9792 & 112 & 27.5 \\
pCm & 0.0238 & 3.74 & 0.9782 & 157 & 42.0 \\
mCm & 0.0305 & 4.06 & 0.9830 & 133 & 32.8 \\
oCm & 0.0222 & 2.56 & 0.9788 & 115 & 45.0 \\
Cin & 0.0185 & 2.31 & 0.9742 & 125 & 54.1 \\
\hline
\end{tabular}

Using the optimized temperature, sulfuric acid concentration, and surfactant concentration, chromatograms for the nine HCA derivatives using Tween 20 and Tween 40 can be compared in Figure 7. In Figure 7A, baseline separation of the nine CA derivatives was achieved within 16 min using Tween 20. Figure 7B represents a chromatogram of the same mixture within 19 min using Tween 40. Peaks in the Tween 20 chromatogram showed only slight peak tailing, with an average asymmetry value of 1.21 for all peaks. The Tween 40 chromatogram showed more significant peak tailing; the average asymmetry of the nine peaks was 2.15. The number of plates $\mathrm{N}$ calculated for $\mathrm{oCm}$ based on baseline peak width was found to be 2886 for Figure 7A and 2039 for Figure 7B. Tween 20 was considered the better option for further quantitative work due to the higher plate count and shorter analysis time.
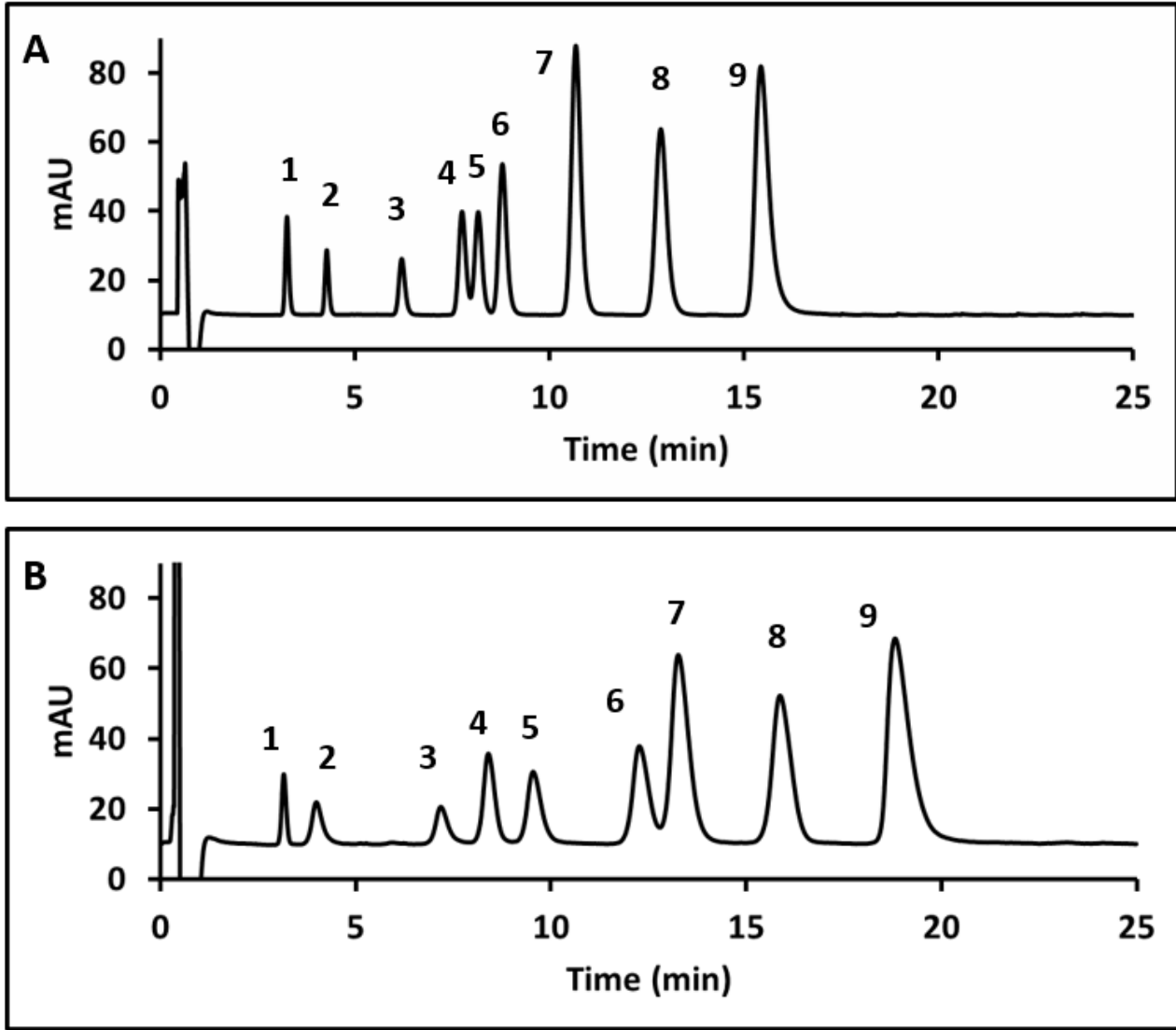

Figure 7. Chromatograms using 1\% Tween 20 (A) and 1\% Tween 40 (B). Peak assignments as follows: 1-CgA, 2- 3,4DHC, 3- SA, 4- FA, 5-Caf, 6- pCm, 7- mCm, 8- oCm, 9- CA. Retention times had \%RSDs between $0.06 \%$ and $2.0 \%$ for Tween 20 and $0.04 \%$ and $2.8 \%$ for Tween 40 . 


\subsection{Analytical Figures of Merit Comparison}

Standard solutions ranging from 10-100 $\mathrm{mg} / \mathrm{L}$ of each HCA derivative were used to calculate the limits of detection (LOD) and limits of quantification (LOQ) in nmoles and in $\mathrm{mg} / \mathrm{L}$ based on a $5 \mu \mathrm{L}$ injection volume. Tables S1 and S2 in the Supplementary Information describe the RSD data for retention factor and peak area, respectively. For the retention factors, RSD values generally ranged between $0.1-3 \%$. For the peak areas, RSD values generally ranged from $0.5-5 \%$. Linear regression analysis parameters, as well as LOD and LOQ, are summarized in Table 6 for Tween 20 and in Table 7 for Tween 40. Comparison of the results shows LOD values ranging from $0.06-0.16$ nmoles $(3-6 \mathrm{mg} / \mathrm{L})$ for both Tween surfactants.

Table 6. Calibration parameters derived from linear regression equations using Tween 20.

\begin{tabular}{ccccccccc}
\hline & $\mathbf{R}^{\mathbf{2}}$ & Intercept & Slope & Std Error & LOD nmoles & LOD mg/L & LOQ nmoles & LOQ mg/L \\
\hline Clg & 0.9987 & -0.253 & 6.401 & 0.13 & 0.061 & 4.319 & 0.203 & 14.4 \\
\hline Dhc & 0.9985 & -0.191 & 2.271 & 0.095 & 0.125 & 4.565 & 0.418 & 15.22 \\
\hline Sip & 0.9986 & -0.247 & 3.776 & 0.124 & 0.099 & 4.434 & 0.33 & 14.78 \\
\hline Fer & 0.9975 & -0.445 & 7.123 & 0.365 & 0.154 & 5.969 & 0.513 & 19.9 \\
\hline Caf & 0.9983 & -0.288 & 6.782 & 0.31 & 0.137 & 4.937 & 0.457 & 16.46 \\
\hline pCm & 0.998 & -0.525 & 9.63 & 0.516 & 0.161 & 5.276 & 0.536 & 17.59 \\
\hline mCm & 0.9988 & -1.703 & 20.85 & 0.886 & 0.127 & 4.184 & 0.425 & 13.95 \\
\hline $\mathbf{o C m}$ & 0.9988 & -1.54 & 17.63 & 0.736 & 0.125 & 4.111 & 0.417 & 13.7 \\
\hline Cin & 0.9988 & -2.916 & 26.54 & 1.234 & 0.14 & 4.133 & 0.465 & 13.78 \\
\hline
\end{tabular}

$\mathrm{LOD}=\left(3^{*} \alpha\right) / \mathrm{B}$, where $\alpha$ is the standard deviation of the $\mathrm{y}$-intercept, $\mathrm{LOQ}=\left(10^{*} \alpha\right) / \mathrm{B}$, where $\alpha$ is the standard deviation of the $y$-intercept.

Table 7. Calibration parameters derived from linear regression equations using Tween 40 .

\begin{tabular}{|c|c|c|c|c|c|c|c|c|}
\hline & $\mathbf{R}^{2}$ & Intercept & Slope & Std Error & LOD nmoles & LOD mg/L & LOQ nmoles & LOQ mg/L \\
\hline $\mathrm{Clg}$ & 0.9976 & -0.105 & 3.563 & 0.080 & 0.068 & 4.781 & 0.225 & 15.95 \\
\hline Dhc & 0.9964 & -0.372 & 2.806 & 0.152 & 0.162 & 5.904 & 0.54 & 19.68 \\
\hline Sip & 0.9967 & -0.123 & 3.273 & 0.139 & 0.127 & 5.969 & 0.423 & 18.99 \\
\hline Fer & 0.9973 & -0.468 & 6.141 & 0.272 & 0.133 & 5.156 & 0.443 & 17.2 \\
\hline Caf & 0.9975 & -0.402 & 5.703 & 0.260 & 0.137 & 4.931 & 0.456 & 16.42 \\
\hline $\mathrm{pCm}$ & 0.9969 & -0.324 & 7.761 & 0.430 & 0.166 & 5.452 & 0.554 & 18.17 \\
\hline $\mathrm{mCm}$ & 0.9987 & -1.537 & 17.27 & 0.632 & 0.109 & 3.604 & 0.366 & 12.01 \\
\hline $\mathrm{oCm}$ & 0.9989 & -0.548 & 13.73 & 0.458 & 0.1 & 3.285 & 0.334 & 10.95 \\
\hline Cin & 0.9978 & -2.4 & 21.75 & 1.141 & 0.158 & 4.661 & 0.525 & 15.54 \\
\hline
\end{tabular}

\subsection{Sample Analysis}

Quantitative analysis was performed using Tween 20, and three samples were analyzed for their HCA derivatives. The organic red wine showed the presence of seven out of the nine HCA derivatives under investigation (Figure 8). To examine the accuracy of this method, the organic red wine sample was spiked with $20 \mathrm{mg} / \mathrm{L}$ of each HCA derivatives (Figure 8) and then the percent recoveries were calculated.

In addition to the two previously mentioned samples, a green coffee extract diet pill was analyzed (Figure 9), showing a major presence of Clg and lower amounts of three other compounds, with trace detection of two more HCAs. The results are listed in Table 8. The percent recoveries of the nine HCA compounds spiked in organic red wine were considered good, ranging from about $90 \%$ to $107 \%$. Although no label information was available for this brand, green coffee diet pills are known to have high amounts of Clg. The "greenness" of this analytical method was evaluated based on a comparison to recently reviewed related liquid chromatography methods [62]. Based on the ECO scale, where 100 is the best, our method should be rated at least in the 90-95 range-similar to mixed micelle MLC studies with no organic modifier, of which only a few such papers were cited. 


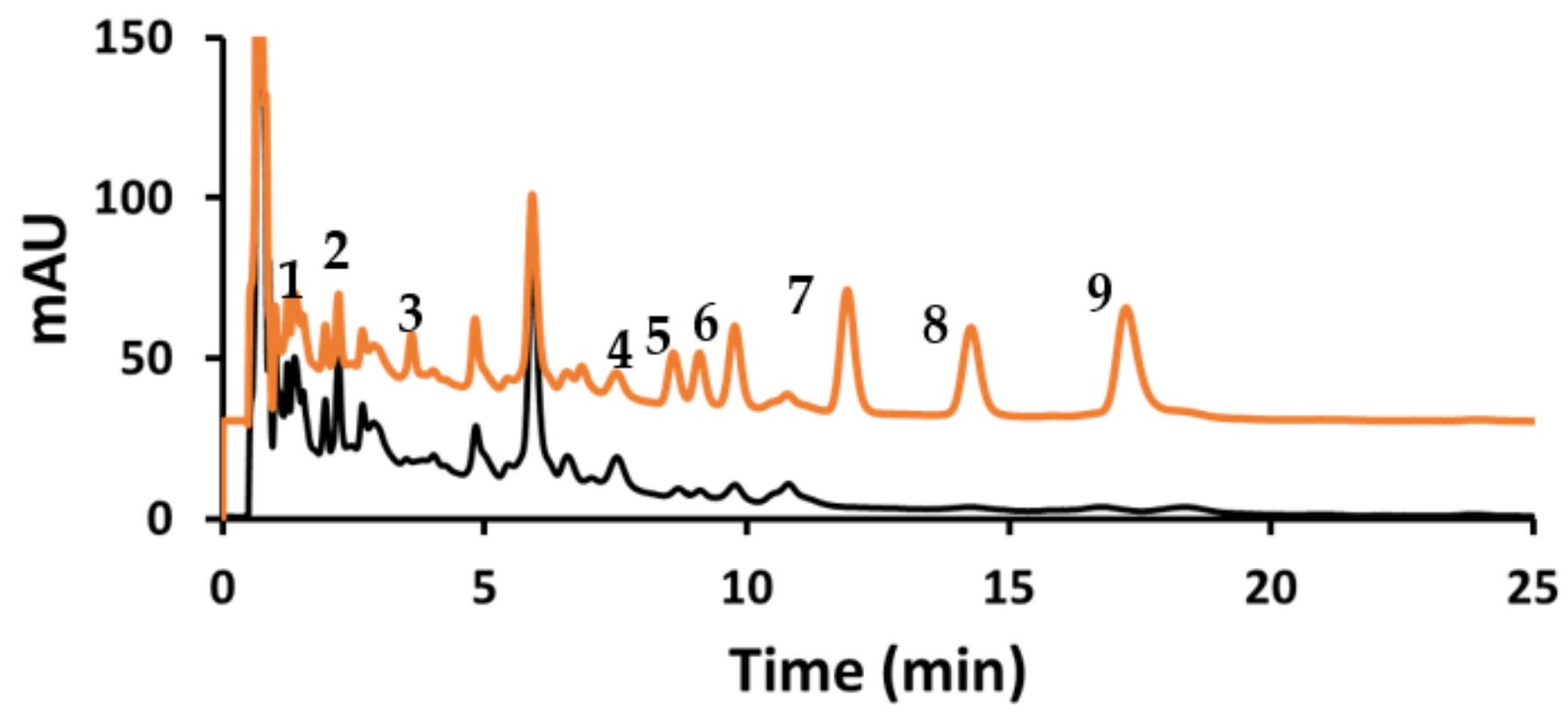

\section{- Red Wine}

\section{- Red Wine Plus 100 ng}

Figure 8. Chromatogram of red wine sample (lower black trace) and spiked red wine to $20 \mathrm{mg} / \mathrm{L}$ of the HCAs (upper orange trace).

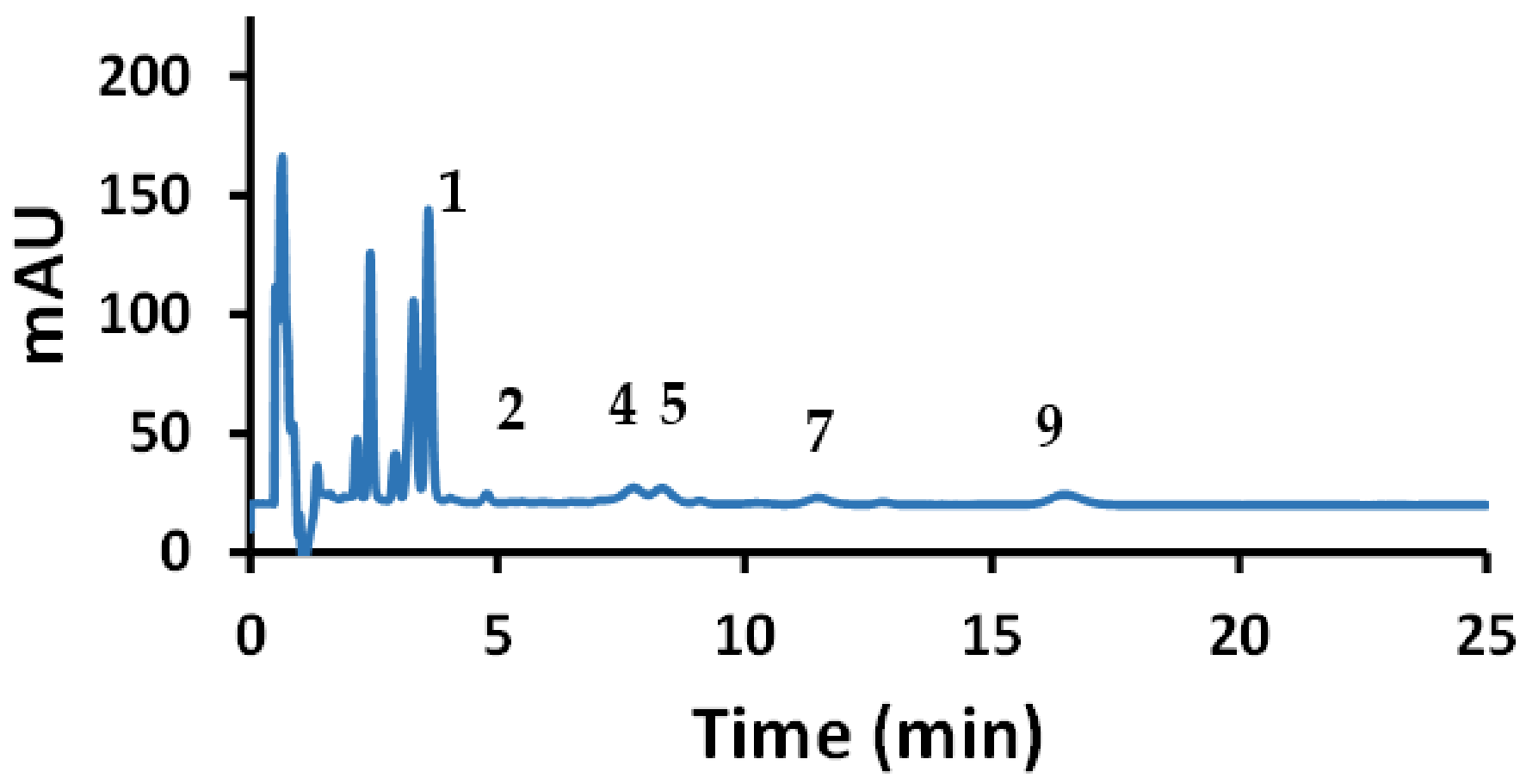

Figure 9. Chromatogram of green coffee diet pill. 
Table 8. The quantitative analysis of the organic red wine and green coffee diet pills. The recovery percentages were calculated by subtracting the amounts of the CA derivatives already found in the sample.

\begin{tabular}{ccccccc}
\hline $\begin{array}{c}\text { Name of } \\
\text { Acid }\end{array}$ & $\begin{array}{c}\text { Red Wine + 100 ng } \\
\text { Spiked HCA }\end{array}$ & $\begin{array}{c}\text { Ng of Acid in } \\
\text { Red Wine }\end{array}$ & $\begin{array}{c}\text { Ppm Acid in } \\
\text { Red Wine }\end{array}$ & \%Recovery & $\begin{array}{c}\text { Ng of Acid in } \\
\text { Green Coffee }\end{array}$ & $\begin{array}{c}\text { Mg Acid } \\
\text { Per Pill }\end{array}$ \\
\hline Clg & 122.6 & 21.43 & 4.286 & 91.14 & 916.1 & 183.2 \\
\hline Dhc & 338.4 & 240.8 & 4.452 & 95.99 & 62.61 & 12.52 \\
\hline Sip & 102.1 & 0 & 0 & 102.1 & 0 & 0 \\
\hline Fer & 121.1 & 17.34 & 3.468 & 103.8 & trace & 15.89 \\
\hline Caf & 125.2 & 28.86 & 5.772 & 91.64 & 92.64 & 179 \\
\hline pCm & 129.2 & 35 & 7 & 107.7 & 0 & 3.639 \\
\hline mCm & 107.7 & 0 & 0 & 99.97 & 0 & 0 \\
\hline oCm & 116.8 & 16.85 & 3.37 & 94.09 & trace & 0 \\
\hline Cin & 115.5 & 21.37 & 4.274 & & \\
\hline
\end{tabular}

\section{Conclusions}

In this study, an ultra-high-performance MLC comparison between Tween 20 and Tween 40 showed optimum mobile phase conditions of $1 \%$ surfactant in $2.5 \mathrm{mM}$ sulfuric acid, with a column temperature of $45^{\circ} \mathrm{C}$. The analytes under investigation were nine hydroxycinnamic acid (HCA) derivatives. Retention of all the HCA compounds was somewhat lower using Tween 20 than Tween 40. The retention order of the HCA compounds was generally as expected, based on the non-polarity of their structure. The retention order of sinapic, ferulic, and caffeic acids were difficult to predict based on structure, but followed a literature-predicted partitioning trend from Tween to a lipid phase. The linearity of the Van't Hoff plots, particularly for Tween 20, indicated one primary retention mechanism.

Based on calculated equilibrium constants, stronger interactions of the more weaklyretained analytes with the Tween 40 micelles were observed. Analytical figures of merit showed LOD values in the $0.06-0.16 \mathrm{nmol}$ range. MLC using Tween 20 as the surfactant in the mobile phase showed faster analysis times (about $15 \mathrm{~min}$ ) and better peak shapes (average 1.2 peak asymmetry) than Tween 40; so, that method was successfully used to analyze two samples directly injected without pre-treatment. The spiked sample experiments showed excellent recoveries.

Supplementary Materials: The following are available online at https:/ /www.mdpi.com/article/10.339 0/separations9030061/s1, Figure S1: Plots of ln retention factor k versus (1/T oK)*1000 using data in Figure 3A for Tween 20; Figure S2: Plots of $\ln$ retention factor $\mathrm{k}$ versus $(1 / \mathrm{T} \mathrm{oK})^{*} 1000$ using data in Figure 3B for Tween 40; Figure S3: Plots of inverse retention factor $1 / \mathrm{k}$ versus Tween 20 concentration (mM) for all HCA compounds; Figure S4: Plots of inverse retention factor 1/k versus Tween 40 concentration (mM) for all HCA compounds. Table S1: \% RSD for retention factor $\mathrm{k}$ for HCA standards and samples; Table S2: \% RSD values for calibration curve hydroxycinnamic acids (HCAs) and HCAs in the samples.

Author Contributions: Conceptualization, A.a.-k.F.A. and N.D.D.; methodology, A.a.-k.F.A.; software, A.a.-k.F.A.; validation, A.a.-k.F.A.; formal analysis, A.a.-k.F.A. and N.D.D.; resources, N.D.D.; writing—original draft preparation, A.a.-k.F.A.; writing—review and editing, N.D.D.; supervision, N.D.D.; project administration, N.D.D. All authors have read and agreed to the published version of the manuscript.

Funding: This research received no external funding.

Institutional Review Board Statement: Not applicable.

Informed Consent Statement: Not applicable.

Data Availability Statement: Not applicable.

Conflicts of Interest: The authors declare no conflict of interest. 


\section{References}

1. Garcia-Alvarez-Coque, M.C.; Torres-Lapasio, J.R.; Navarro-Huerta, J.A. Secondary chemical equilibria in reversed-phase liquid chromatography. In Liquid Chromatography, Fundamentals and Instrumentation, 2nd ed.; Fanali, S., Haddad, P.R., Poole, C.F., Riekkola, M.-L., Eds.; Elsevier: Amsterdam, The Netherlands, 2017; Chapter 5; pp. 125-146.

2. Unal, D.R.; Yildirim, S.; Kurbanoglu, S.; Uslu, B. Current trends and roles of surfactants for chromatographic and electrochemical sensing. Trends Anal. Chem. 2021, 14, 116418. [CrossRef]

3. Stepnik, K.E.; Malinowska, I.; Roj, E. Micellar liquid chromatography of plant extracts components. J. Planar Chrom. 2014, 27, 420. [CrossRef]

4. Prutthiwanasan, B.; Suntornsuk, L. Improved resolution of fluoroquinolines using cetyltrimethylammonium bromide micellar electrokinetic chromatography and its application to residue analysis in surface water. J. Chromatog. B 2018, 1092, 306-312. [CrossRef] [PubMed]

5. Borgerding, M.F.; Hinze, W.L. Characterization and Evaluation of the Use on Nonionic Polyoxyethylene(23)dodecanol Micellar Mobile Phases in Reversed Phase High Performance Liquid Chromatography. Anal. Chem. 1985, 57, 2183-2190. [CrossRef]

6. Ke, J.; Duan, X.-Y.; Liu, X.-F.; Dong, Y.-M. Isocratic micellar liquid chromatography using mixed anionic and non-ionic surfactants as mobile phase additives for separation of 17 amino acids. Chem. Papers 2019, 73, 2417-2426. [CrossRef]

7. Ibrahim, A.E.; Elmaaty, A.A.; El-Sayed, H.M. Determination of six drugs used for treatment of common cold by micellar liquid chromatography. Anal. Bioanal. Chem. 2021, 413, 5051-5065. [CrossRef] [PubMed]

8. Duan, X.; Liu, X.; Dong, Y.; Duan, T.; Zhang, J.; He, S.; Yang, F.; Dong, Y. A mixed micellar liquid chromatography with direct detection for rapid analysis of eight sulfonamides in milk. Food Anal. Methods 2020, 13, 1148-1158. [CrossRef]

9. Peris-García, E.; Rodríguez-Martínez, J.; Baeza-Baeza, J.J.; García-Alvarez-Coque, M.C.; Ruiz-Angel, M.J. Search of Non-Ionic Surfactants Suitable for Micellar Liquid Chromatography. Anal. Bioanal. Chem. 2018, 410, 5043-5057. [CrossRef]

10. Yabre, M.; Ferey, L.; Touridomon Some, I.; Gaudin, K. Greening reversed-phase liquid chromatography methods using alternative solvents for pharmaceutical analysis. Molecules 2018, 23, 1065. [CrossRef]

11. Fasciano, J.M.; Danielson, N.D. Micellar and Sub-Micellar Ultra-High Performance Liquid Chromatography of Hydroxybenzoic Acid and Phthalic Acid Positional Isomers. J. Chromatogr. A 2016, 1438, 150-159. [CrossRef]

12. Richardson, A.E.; McPherson, S.D.; Fasciano, J.M.; Pauls, R.E.; Danielson, N.D. Micellar liquid chromatography of terephthalic acid impurities. J. Chromatog. A 2017, 1491, 67-74. [CrossRef] [PubMed]

13. Ali, A.F.; Danielson, N.D. Micellar and sub-micellar liquid chromatography of terephthalic acid contaminants using a C18 column coated with Tween 20. Anal. Chim. Acta 2020, 1105, 214-223. [CrossRef]

14. Patyra, E.; Kwiatek, K. Analytical capabilities of micellar liquid chromatography and application to residue and contaminant analysis. A review. J. Sep. Sci. 2021, 44, 2206-2220. [CrossRef] [PubMed]

15. Haupt, D.; Pettersson, C.; Westerlund, D. Separation of (R)- and (S)-naproxen using micellar chromatography and an a1-acidglycoprotein column: Application for chiral monitoring in human liver microsomes by coupled column chromatography. $J$. Biochem. Biophys. Methods 1992, 25, 273-284. [CrossRef]

16. Haupt, D.; Pettersson, C.; Westerlund, D. Enantiomeric separations of remoxipride, propranolol, and trimipramine on Chiral-AGP using micellar chromatography and anionic additives. Chirality 1993, 5, 224-228. [CrossRef]

17. Haupt, D.; Pettersson, C.; Westerlund, D. Retention model for the resolved enantiomers of felodipine on chiral-AGP using micellar mobile phases. Chirality 1995, 7, 23-27. [CrossRef]

18. Lövgren, U.; Johansson, M.; Kronkvist, K.; Edholm, L.E. Biocompatible Sample Pretreatment for Immunochemical Techniques Using Micellar Liquid Chromatography for Separation of Corticosteroids. J. Chromatogr. B Biomed. Sci. Appl. 1995, 672, 33-44. [CrossRef]

19. Rukhadze, M.D.; Sebiskveradze, M.V.; Akhalkatsi, T.G.; Makharadze, T.G. Imitation of artificial membrane system via mobile phases with Tween-80 and cholic acid in biopartitioning micellar chromatography. Biomed. Chromatog. 2006, 20, 753-759. [CrossRef] [PubMed]

20. Liu, L.; Liu, X.; Chen, X.; Hu, Z. Separation and determination of tetrandrine and fangchinoline in herbal medicines by flow injection-micellar electrokinetic capillary chromatography with internal standard method. J. Chromatogr. A 2005, 1098, 177-182. [CrossRef]

21. Medford, I.N. Modification of reversed-phase separations of small molecules using non-ionic surfactants and mixed ionic-nonionic surfactants. J. Chromatogr. 1986, 368, 31-37. [CrossRef]

22. Pekkarinen, S.S.; Stockmann, H.; Schwarz, K.; Heinonen, I.M.; Hopia, A.I. Antioxidant activity and partitioning of phenolic acids in bulk and emulsified methyl linoleate. J. Agric. Food Chem. 1999, 47, 3036-3043. [CrossRef] [PubMed]

23. Mathew, S.; Abraham, T.E. Ferulic Acid: An Antioxidant Found Naturally in Plant Cell Walls 381 and Feruloyl Esterases Involved in Its Release and Their Applications. Crit. Rev. Biotechnol. 2004, 24, 59-83. [CrossRef] [PubMed]

24. Fazary, A.E.; Ju, Y.H. Feruloyl Esterases as Biotechnological Tools: Current and Future Perspectives. Acta Biochim. Biophys. Sin. 2007, 39, 811-828. [CrossRef]

25. Sgarbossa, A.; Giacomazza, D.; Di Carlo, M. Ferulic Acid: A Hope for Alzheimer's Disease Therapy from Plants. Nutrients 2015, 7, 5764-5782. [CrossRef]

26. Ou, S.; Kwok, K.C. Ferulic Acid: Pharmaceutical Functions, Preparation and Applications in Foods. J. Sci. Food Agric. 2004, 84, 1261-1269. [CrossRef] 
27. Kumar, N.; Pruthi, V. Potential Applications of Ferulic Acid from Natural Sources. Biotechnol. Separations 2014, 4, 86-93. [CrossRef]

28. Solecka, D. Role of Phenylpropanoid Compounds in Plant Responses to Different Stress Factors. Acta Physiol. Plant. 1997, 19, 257-268. [CrossRef]

29. Salvador, V.H.; Lima, R.B.; dos Santos, W.D.; Soares, A.R.; Böhm, P.A.F.; Marchiosi, R.; de Ferrarese, M.L.L.; Ferrarese-Filho, O. Cinnamic Acid Increases Lignin Production and Inhibits Soybean Root Growth. PLoS ONE 2013, 8, e69105. [CrossRef]

30. Ferro, A.P.; Marchiosi, R.; Siqueira-soares, R.D.C.; Bonini, E.A. Effects of Cinnamic and Ferulic Acids on Growth and Lignification of Maize Roots. J. Allelochem. Interact. 2015, 2015, 29-38.

31. El-Seedi, H.R.; El-Said, A.M.A.; Khalifa, S.A.M.; Göransson, U.; Bohlin, L.; Borg-Karlson, A.K.; Verpoorte, R. Biosynthesis, Natural Sources, Dietary Intake, Pharmacokinetic Properties, and Biological Activities of Hydroxycinnamic Acids. J. Agric. Food Chem. 2012, 60, 10877-10895. [CrossRef] [PubMed]

32. De, P.; Baltas, M.; Bedos-Belval, F. Cinnamic Acid Derivatives as Anticancer Agents-A Review. Curr. Med. Chem. 2011, 18, 1672-1703. [CrossRef]

33. Cosme, F.; Pinto, T.; Vilela, A. Phenolic Compounds and Antioxidant Activity in Grape Juices: A Chemical and Sensory View. Beverages 2018, 4, 22. [CrossRef]

34. Lin, I.-J.; Cham, T.-M.; Wu, S.-M. Simultaneous Determination of Hesperidin, Ferulic Acid, Cinnamic Acid and Cinnamaldehyde in Chinese Tonic Wine by High Performance Liquid Chromatography. J. Chin. Chem. Soc. 2010, 57, 429-435. [CrossRef]

35. Singleton, V.L.; Timberlake, C.F.; Lea, A.G.H. The Phenolic Cinnamates of White Grapes and Wine. J. Sci. Food Agric. 1978, 29, 403-410. [CrossRef]

36. Gonçalves, J.; Silva, C.L.; Castilho, P.C.; Câmara, J.S. An Attractive, Sensitive and High-Throughput Strategy Based on Microextraction by Packed Sorbent Followed by UHPLC-PDA Analysis for Quantification of Hydroxybenzoic and Hydroxycinnamic Acids in Wines. Microchem. J. 2013, 106, 129-138. [CrossRef]

37. Canas, S. Phenolic Composition and Related Properties of Aged Wine Spirits: Influence of Barrel Characteristics. A Review. Beverages 2017, 3, 55. [CrossRef]

38. Prosekov, A.Y.; Mudrikova, O.V.; Babich, O.O. Determination of Cinnamic Acid by Capillary Zone Electrophoresis Using Ion-Pair Reagents. J. Anal. Chem. 2012, 67, 474-477. [CrossRef]

39. Zhu, L.; Zhang, Y.; Lu, J. Phenolic Contents and Compositions in Skins of Red Wine Grape Cultivars among Various Genetic Backgrounds and Originations. Int. J. Mol. Sci. 2012, 13, 3492-3510. [CrossRef]

40. Ilc, T.; Werck-reichhart, D.; Navrot, N. Meta-Analysis of the Core Aroma Components of Grape 424 and Wine Aroma. Front. Plant Sci. 2016, 7, 1472. [CrossRef]

41. Atanackovi, M.; Cveji, J. Development of HPLC Method for Determination of Phenolic Compounds on a Core Shell Column by Direct Injection of Wine Samples. Acta Chromatogr. 2020, 32, 134-138.

42. Rouseff, R.L.; Seetharaman, K.; Naim, M.; Nagy, S.; Zehavi, U. Improved HPLC Determination of Hydroxycinnamic Acids in Orange Juice Using Solvents Containing THF. J. Agric. Food Chem. 1992, 40, 1139-1143. [CrossRef]

43. Irakli, M.N.; Samanidou, V.F.; Biliaderis, C.G.; Papadoyannis, I.N. Development and validation of an HPLC-method for determination of free and bound phenolic acids in cereals after solid-phase extraction. Food Chem. 2012, 134, 1624-1632 [CrossRef] [PubMed]

44. Nour, V.; Trandafir, I.; Cosmulescu, S. HPLC determination of phenolic acids, flavonoids, and juglone in walnut leaves. J. Chrom. Sci. 2013, 51, 883-890. [CrossRef] [PubMed]

45. Magiera, S.; Zaeba, M. Chromatographic determination of phenolic acids and flavonoids in Lycium barbarum L. and evaluation of antioxidant activity. Food Anal. Methods 2015, 8, 2665-2674. [CrossRef]

46. Spacil, Z.; Novakova, L.; Solich, P. Analysis of phenolic compounds by high performance liquid chromatography and ultraperformance liquid chromatography. Talanta 2008, 76, 189-199. [CrossRef] [PubMed]

47. Jimenez, M.S.; Velarte, R.; Castillo, J.R. Direct determination of phenolic compounds and phospholipids in virgin olive oil by micellar liquid chromatography. Food Chem. 2007, 100, 8-14. [CrossRef]

48. Hadjmohammadi, M.R.; Mousavi Kiasari, Z.; Nazari, S.S.S.J. Separation of some phenolic acids in micellar liquid chromatography using design of experiment-response surface methodology. J. Anal. Chem. 2016, 71, 610-616. [CrossRef]

49. Hadjmohammadi, M.R.; Nazari, S.S.S.J. Simultaneous isocratic separation of phenolic acids and flavonoids using micellar liquid chromatography. J. Sep. Sci. 2013, 36, 3667-3672. [CrossRef]

50. Peris-Garcia, E.; Ortiz-Bolsico, C.; Baeza-Baeza, J.J.; Garcia-Alvarez-Coque, M.C. Isocratic and gradient elution in micellar liquid chromatography with Brij-35. J. Sep. Sci. 2015, 38, 2059-2067. [CrossRef]

51. Navarro-Huerta, J.A.; Vargas-Garcia, A.G.; Torres-Lapasio, J.R.; Garcia-Alvarez-Coque, M.C. Interpretative search for optimal isocratic and gradient separations in micellar liquid chromatography in extended organic solvent domains. J. Chromatogr. A 2020, 1616, 460784. [CrossRef]

52. El-Shaheny, R.N.; El-Maghrabet, M.H.; Belal, F.F. Micellar Liquid Chromatography from Green Analysis Perspective. Open Chem. 2015, 13, 877-892. [CrossRef]

53. Hait, S.K.; Moulik, S.P. Determination of critical micelle concentration (CMC) of nonionic surfactants by donor-acceptor interaction with iodine and correlation of CMC with hydrophile-lipophile balance and other parameters of the surfactants. J. Surfact. Deterg. 2001, 4, 303-309. [CrossRef] 
54. Mahmood, M.E.; Al-Koofee, D.A.F. Effect of temperature changes on critical micelle 488 concentration for Tween series surfactant. Glob. J. Sci. Front. Res. Chem. 2013, 13, 1-7.

55. Gilpin, R.K.; Squires, J.A. Effect of temperature on the orientation of bonded hydrocarbon phases in totally aqueous liquid chromatographic systems. J. Chrom. Sci. 1981, 19, 195-199. [CrossRef]

56. Delgado Rodriguez, M.A.; Sanchez, M.J.; Gonzalez, V.; Montelongo, F.G. Role of temperature in the behavior of PAHs in micellar liquid chromatography. Thermodynamic aspects. J. Chrom. Sci. 1995, 33, 647-653. [CrossRef]

57. Tanase, M.; Soare, A.; David, V.; Moldoveanu, S.C. Sources of nonlinear Van't Hoff temperature dependence in high performance liquid chromatography. ACS Omega 2019, 4, 19808-19817. [CrossRef]

58. Sander, L.C.; Wise, S.A. Sub-ambient temperature modification of selectivity in reversed-phase liquid chromatography. Anal. Chem. 1989, 61, 1749-1754. [CrossRef]

59. Arunyanart, M.; Cline Love, L.J. Model for micellar effects on liquid chromatography capacity factors and for determination of micelle-solute equilibrium constants. Anal. Chem. 1984, 56, 1557-1561. [CrossRef]

60. Ludwig, M.; Geisler, R.; Prevost, S.; von Klitzing, R. Shape and structure formation of mixed nonionic-anionic surfactant micelles. Molecules 2021, 26, 4136. [CrossRef]

61. Bester-Rogac, M. Micellar properties of nonionic surfactant Tween 40 in water: Small-angle x-ray scattering study. Acta. Chim. Slov. 2007, 54, 452-459.

62. Kannaiah, K.P.; Sugumaran, A.; Chanduluru, H.K.; Rathinam, S. Environmental impact of greenness assessment tools in liquid chromatography-A review. Microchem. J. 2021, 179, 106685. [CrossRef] 